\title{
The S-Curve of Technological Adoption: Mobile Communication Devices on Commuter Trains in the Chicago Region, 2010-2015
}

Joseph P. Schwieterman, Ph.D.

DePaul University

Lauren Ames Fischer

Columbia University

\begin{abstract}
Urban transit riders' use of mobile communication devices has grown markedly in recent years. Studies evaluating the usage of these devices have generally focused on only one or two points in time, limiting their ability to describe long-range trends. To foster insights into this issue, this study evaluated data from 15,531 passenger observations collected on 156 commuter trains on the metropolitan commuter rail system of Chicago, Illinois, from 2010 through 2015. The data show that the rate of technological usage is following an S-shaped pattern among passengers. The share of passengers using mobile communication devices at observed points grew sharpest during the first three years, rising from $25.6 \%$ in 2010 to $47.8 \%$ in 2013, a compounding annual rate of $23.1 \%$. Between 2013 and 2015, the share rose to 56.2\%, an annualized rate of just $8.4 \%$. Over the five-year period, the share of passengers conducting visually-oriented activities on their devices increased at a faster rate than usage as a whole, whereas the share of passengers engaged in audio-only tasks has dropped. Multiple regression analysis shows that the rate of device usage on trains is highest on outbound trips (traveling away from downtown) and positively related to the income associated with the route traveled, with differences of more than five percentage points between lines of varying levels of affluence.
\end{abstract}

Keywords: Public transportation, technology, mobile communication devices 


\section{Introduction}

Many passengers on urban transit systems routinely use mobile communication devices ("mobile devices") while making their journey. Mobile devices such as smartphones and tablet computers enable passengers to perform work or leisure activities, access travel information, and insulate themselves from the noise and distractions normally experienced during their trip. As devices have become smaller, less costly, and more sophisticated, the range of activities performed by passengers has grown sharply.

This study documented the changing prevalence of mobile device use among commuter rail riders in metropolitan Chicago to assess how changes in technology affect the way passengers allocate their time while using commuter rail. The study draws upon 15,531 unique passenger observations collected on 156 suburban Metra trains in the Chicago metropolitan area between 2010 and 2015. Although other studies have explored the use of mobile devices on transit systems, this study is unique in providing a time-series assessment for a five-year period, allowing the authors to gauge how the use of mobile devices has changed over time and to identify trends in technology use by travelers that may aid in the planning and management of urban transportation.

The results can help guide the discussion about how transit agencies can take advantage of a growing range of digital activities available to passengers as well as respond to the "digital divide" that persists among various income groups in the use of technology. Finally, the data can help transit agencies evaluate the need for enhancements that support technology use among passengers that have been unable or hesitant to extensively use mobile devices as part of their journey.

\section{Background}

As recently as the late 1980s, most electronic devices were too bulky and had a battery life that was too limited to be conveniently brought onto buses and trains (Farley 2005). Passengers generally had little or no ability to communicate with anyone except fellow travelers onboard. When communication technology first became available to travelers, it was available exclusively on intercity (longer-distance) services rather than on urban public transit. The first commercial cellular phone service in the United States was introduced in early 1969 on Metroliner trains between New York and Washington, DC (Farley 2005), and airline carriers first installed cellular phones in the early 1980s, which could be used by customers paying with a credit card. By the late 1990s, pay phones also had become available on many intercity rail-passenger routes in Europe and North America.

Technological innovation made spectacular advances by the late 1990 s as cell phones and laptop computers became smaller, less expensive, and more sophisticated. These advances were followed, in the early 2000 s by devices oriented toward multitasking, such as smartphones. More recently, tablets and e-readers have further enhanced the ease of personal entertainment and communication for passengers, a topic discussed in detail later in this paper. 
Some public transit operators have responded to these trends by investing in $\mathrm{Wi}-\mathrm{Fi}$ systems on buses, and a smaller number have done so on commuter trains. The transit system in Albuquerque, New Mexico, for example, installed Wi-Fi on its trains in 2005, making it a pioneer in expanding internet access for passengers. In 2008, the transit operator in Boston (MBTA) launched a pilot program for the installation of Wi-Fi and has since made it available on nearly the entire system (MBTA 2013). In 2009, the Bay Area Rapid Transit (BART) system began providing wireless service on a portion of its system, and since then, commuter rail operators in Miami, Minneapolis-St. Paul, and New Jersey have also selectively installed Wi-Fi. Transportation systems outside the US also have offered these amenities to their passengers.

Nevertheless, the number of commuter rail systems that have installed Wi-Fi on their entire fleet remains relatively small. In Chicago, the suburban operator Metra did not offer Wi-Fi at the time data were collected for this study. The provider initially determined that offering the amenity on all its railcars was cost-prohibitive but adopted a plan for introducing Wi-Fi service on an experimental basis in selected cars on some of its trains in 2016 (Metra 2015).

\section{Relevant Literature}

The literature on the adoption of technology is shaped by Everett Rogers' seminal work Diffusion of Innovations, which attempts to explain how, why, and at what rate new ideas and technology spread through cultures. A major contribution of Rogers' work lies in his categorization of technology adopters based on their propensity to embrace new ideas, including the popular term "early adopter." His work shows that rates of adoption tend to follow an S-shaped pattern that is affected by innovations, communication, social influences, and other factors (Rogers 1962). By the time the "late majority" adopts a technology, growth has sharply diminished (Figure 1).

FIGURE 1.

S-curve model of diffusion process (adopted from Rogers 1962).

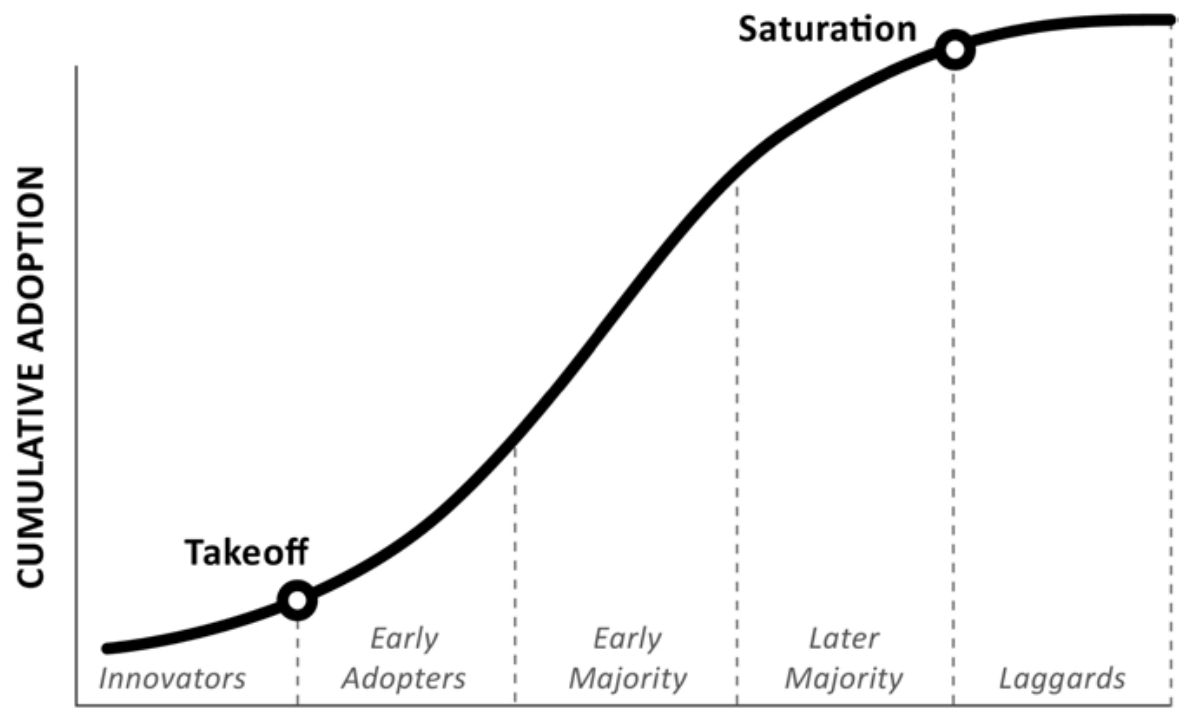

TIME 
Several decades would pass before mobile communication devices became a factor in decisions relating to urban travel. Gradually, however, as cell phones and other devices became prevalent, research drew upon Rogers' ideas to explore the complex interactions between technology and travel behavior (Andrew 2010; Golob and Regan 2001). Kim et al. (2008) examined how people use technology to plan for personal and business travel, while Yoshii and Sasaki (2010) studied how technology affects the need for non-business travel, focusing particularly on consumer behavior and online shopping. Much has changed, of course, since these studies were published.

Brakewood et al. (2014) use a stated preference survey of passengers on a pair of commuter rail lines in the Boston region to assess the degree to which passengers use mobile communication devices for mobile ticketing. The study concludes that among the approximately $76 \%$ of riders that used smartphones in $2012,26 \%$ used them for mobile ticketing and $50 \%$ used them for making mobile purchases at other merchants. A related strand of research explored the varying rates of technology use by different socioeconomic groups while traveling (Jackson et al. 2008; Kim et al. 2008). A consulting firm, Ninth Decimal (2015), tracked the types of devices used by consumers when researching and purchasing tickets for transportation as well as the share of consumers relying on public Wi-Fi for these tasks.

Windmiller et al. (2014), through a survey of passengers on the light rail system in St. Louis, showed that passengers who use smartphones or access electronic messages, including emails and texts, tend to be more satisfied with their travel experience. These passengers also report greater feelings of personal security at transit stations and higher service quality when making connections. This study also demonstrated how rates of technology use are rising; whereas just $52 \%$ of passengers used their phone's text messaging capability in 2008, the number rose to $88 \%$ in 2012. A study by Tang and Thakuriah (2010), focused on bus routes in Chicago, concluded that providing passengers access to real-time information on their smartphones fosters a slight increase in ridership compared to routes on which this was unavailable. The study isolates this effect while controlling for a wide variety of neighborhood-specific variables. Following a similar theme, Barbeau et al. (2010) explored how new mobile apps enhance rider experience by providing real-time information about their trips, including alerting customers when to disembark or enabling riders to signal the driver to stop. Guo et al. (2015) observed 1,739 passengers and surveyed 686 to evaluate usage patterns on the bus system in Vancouver, British Columbia. Their study used a predictive model to evaluate the factors (such as crowding and waiting conditions) that affect how riders spend their time.

Particularly relevant to the present study is the analysis of how mobile communication use affects the perceived cost of travel. Some of the most extensive research on this topic has been undertaken by Mokhtarian and Solomon, whose 2001 paper provides a framework for evaluating the value of time spent on buses and trains (Mokhtarian and Salomon, 2001). Their analysis, based on a study of residents in the San Francisco Bay Area, contested the notion that travel is purely a derived demand by providing evidence that many travelers take pleasure in the trip itself and benefit from the activities they conduct while making the trip. A later paper by Mokhtarian and Salomon (2014) 
evaluated the utility that passengers gain from time spent traveling via train through Great Britain and showed that travelers derive significant benefit from the technology they bring with them. Lyons et al. (2012) employed similar methods to measure how rail passengers in Great Britain spent their travel time from 2004 and 2010. Not only did technology use dramatically increase for the three types of trips evaluated over this period-commuting, business, and leisure-but certain activities, such as listening to music, more than doubled in most categories considered.

Several other studies evaluated some of the psychological aspects of having the ability to use technology. Jain and Lyons (2008) were early contributors to this area of research by exploring how time spent traveling often is perceived as a gift that affords travelers transition time in such a way that it fills a need for "experiencing distance and the opportunity for gearing up to the destination's demands" (83). Another benefit these authors identify is providing a "time out," i.e., the opportunity to escape from obligations and provide "backstage" time to make a mental transition from one activity to another.

Ohmori and Harata (2008) showed that the amount of personal space available influences technology activity, and Holley et al. (2008) postulated that the value of travel time on trains is closely linked to passenger ability to perform tasks using devices. The interaction between technology use and traveler behavior also is explored by Simun (2000), Bull (2000), and Skanland (2011).

The final group of relevant research looks specifically at the effects of personal technology across modes on longer distance intercity trips. Hess and Spitz (2015), evaluating data from the Northwest and West Coast corridors, concluded that a desire to use technology has a positive effect on the propensity to travel by train and bus compared to driving for trips between 200 and 350 miles. Nevertheless, their research also shows that the importance passengers place on using mobile devices is small when compared to other factors, such as schedule convenience. Russell et al. (2011) observed bus and train riders in New Zealand, concluding that bus travelers are less apt to use mobile devices than train riders.

In summary, a rich body of literature explores the ramifications of the growing use of mobile communication devices on transit. What remains less clear is how the rate of growth in mobile device usage has changed in recent years, and the extent to which growth has followed the S-shaped pattern postulated by Rogers (1962). This study seeks to fill this gap in the literature by presenting findings from a five-year observational study on mobile device usage by commuters in one metropolitan region.

\section{Chicago's Commuter Rail System}

The metropolitan Chicago region offers a rich environment for exploring the use of mobile communication devices in urban travel. It is home to one of the most extensive commuter rail systems in North America and consists primarily of routes that date back to the 1800s and radiate from the central city (known as "The Loop"). Most of these routes were operated by profitable railroads through the 1950s or 1960s until the 
private automobile became affordable to a wider range of income groups. As services became increasingly unprofitable, Chicago-area residents approved a referendum in 1973 to create the Regional Transportation Authority to subsidize commuter rail, bus, and rail rapid-transit services in the metro area.

The region's commuter rail system, branded as Metra, currently has a 292,000 average weekday ridership over 11 main lines and 4 branch lines radiating out of downtown Chicago (APTA 2016). These lines depart from one of four downtown terminals to 237 outlying stations. Metra owns, maintains, and directly operates four of these main lines as well as three branches, and the others are operated under contract with private railroads. Metra's ridership has grown markedly in recent years; after modest declines in 2012, partially due to a fare increase, ridership grew 3\% in 2013 and 12\% in 2014. Ridership was also up slightly in 2015 (Metra 2016).

There is limited research on the factors affecting technology use among Chicago-area transit riders. Two studies looked specifically at factors affecting technology use among this group. Frei and Mahmassani (2011) administered a survey to Chicago Transit Authority passengers and determined that demographic issues and the quality of the environment significantly affect technology use. Older adults were found to be less likely to use devices than younger travelers, and females more likely than men. The other body of work relies on various passenger surveys commissioned by Metra. A 2011 survey showed that about half of all Metra riders used a smartphone during their trip, $27 \%$ carried a laptop, and $6 \%$ had a wireless card they could use while traveling (Metra 2013). Relatively few passengers (about $11 \%$ ) report being willing to pay a fee for wi凶fi on board. A 2014 survey showed that $66 \%$ of passengers noted that the ability to "read/ work/nap" was important to them (Metra 2015). The survey, however, did not include questions focusing specifically on mobile devices.

\section{Methodology}

The data presented below were part of Technology in Travel, a multi-year project that involved direct observation of passengers on various modes of transportation between 2010 and 2015. To measure the use of mobile communication devices among passengers, a data team passed through the aisles of buses and trains to record data on passenger technology device usage. Data collectors traveled as regular fare-paying passengers and collected data in real-time settings. To allow for greater consistency in comparisons among modes, this study considered only weekday trips.

Data collection began 10 minutes after leaving the station to ensure that passengers had time to get situated. Data were collected only on weekdays between 8:30 AM and 7:30 PM. The sample size differed by train, depending on the passenger load and time available for data collection. The data collection team adhered to a consistent protocol when responding to situations that created issues for data quality. For example, when two passengers are using the same device, only the passenger most closely situated to the device was counted as using the device, making our estimates conservative. Passengers who appeared to be below grade-school age ( $5^{\text {th }}$ grade or younger) 
were excluded from the observational count. Passengers using a set of earbuds or headphones plugged into an electronic device and who appeared to be sleeping were counted as using an audio device. Only when clear and unobstructed views were possible did the team record data of passengers sitting on upper levels of gallery cars. "Quiet cars" (in service only during peak periods), in which talking is banned, were not included in the sample. The number of riders observed on routes extending north, northwest, west, south, and southwest of the city was based on each region's share of total ridership. The number of observations by region is depicted in Figure 2 .

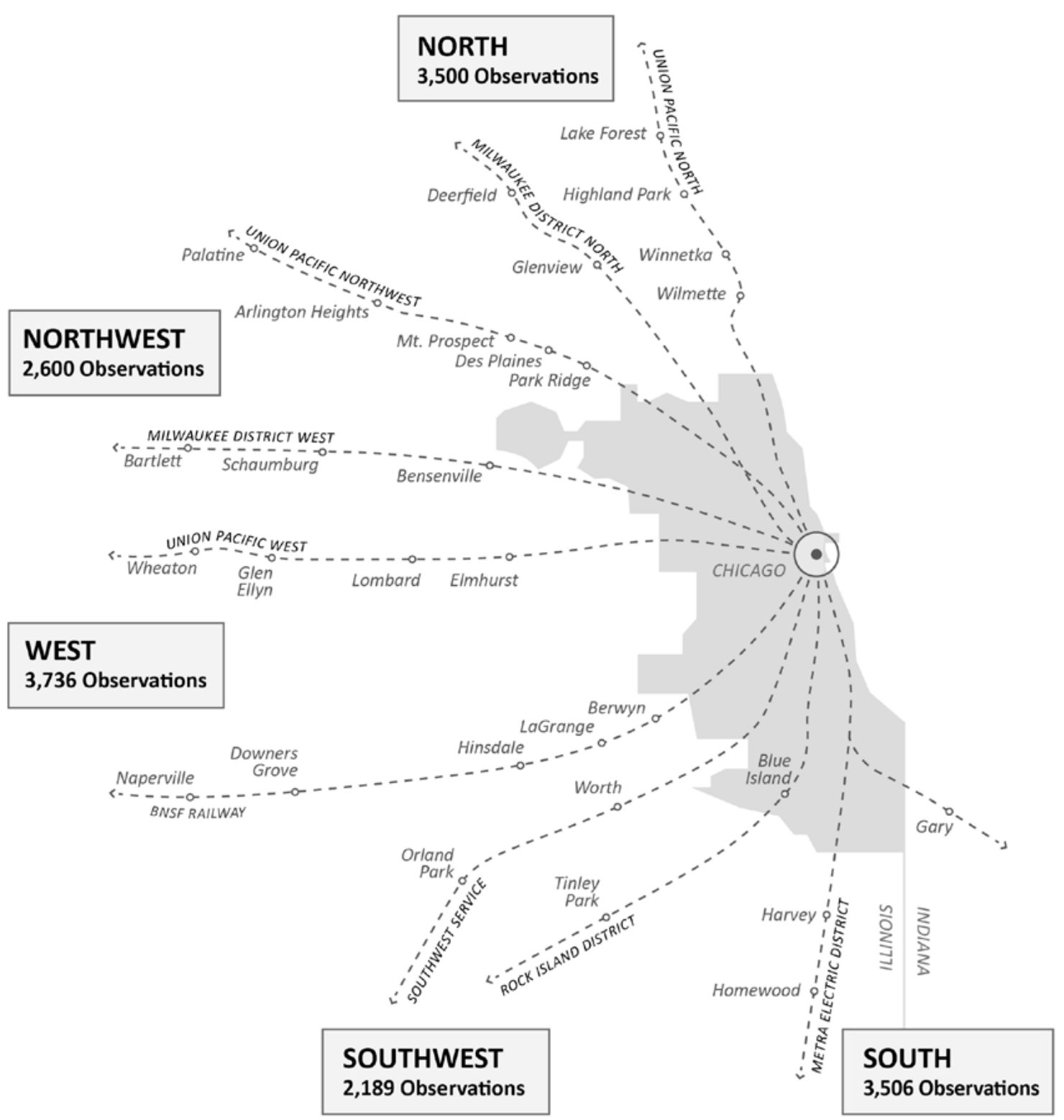

FIGURE 2. Passenger observations on commuter rail services in metropolitan Chicago, 2010-2015.

Sample size by regional subcategory. 
In addition to counting the number of passengers using an electronic device, data collectors also categorized each type of observed device use based on the type of activity being conducted by passengers (Table 1). Categories denoted whether a passenger was using a mobile device and, if so, whether the task was strictly audio (such as listening to music or talking on a cellular phone), visual, or audio-visual in orientation (these tasks typically involve using an LCD screen). Tablets and e-readers (including "phablets"-mobile devices that straddle the size of smartphones and tablets) were broken out into a separate category from other visually-oriented (LCD) devices starting in 2012.

TABLE 1.

\begin{tabular}{|l|l|}
\hline \multicolumn{1}{|c|}{ Activity } & \multicolumn{1}{c|}{ Description } \\
\hline No technology being used & Passenger not engaged with personal electronic device. \\
\hline Audio activities & $\begin{array}{l}\text { Passenger engaged in a task such as those involving cellphones or } \\
\text { music players that can be used with earphones, speakers, or headsets, } \\
\text { using only audio functions of mobile communication devices. }\end{array}$ \\
\hline $\begin{array}{l}\text { Visual or audiovisual activities } \\
\text { on devices, not including iPads, } \\
\text { Kindles, and other tablet use }\end{array}$ & $\begin{array}{l}\text { Passenger engaged in visual or audiovisual features on laptop } \\
\text { computers, Blackberries and other smartphones, DVD players, and } \\
\text { iPods (includes any traveler looking at LCD screen for purpose of } \\
\text { engaging in activity more substantial than placing a phone call). }\end{array}$ \\
\hline $\begin{array}{l}\text { Visual or audio-visual activities } \\
\text { on iPads, Kindles, and other } \\
\text { tablets or "phablets" }\end{array}$ & $\begin{array}{l}\text { Same as Category 2 except focusing specifically on tablet and } \\
\text { "phablet" use. Category introduced in 2012 to capture how small, } \\
\text { lightweight devices affect traveler behavior. }\end{array}$ \\
\hline
\end{tabular}

Data collection on passenger use of mobile devices began in 2010 and continued annually through 2015. For the first two years of the study (2010 and 2011), data were collected from December through March. In the following years (2012-2015), data were collected between January and May. The above issues may affect comparisons between the first two years of data collection and the last three years if it is assumed that technology use on transit varies considerably by month. The experience with this project suggests that this change in the months during which data collection occurred does not considerably change the conclusions presented herein.

As noted in Table 2, the number of passenger observations gradually grew from about 1,400 in 2010 and 2011, to 2,737 in 2012, 3,478 in 2013, and more than 4,000 in the final year. The sample was purposely expanded to allow for the analysis of sub-regional differences in usage (a topic considered in this paper by evaluating the effects of income differences along different lines). The number of trains sampled rose from 14 in 2010, to 18 in 2011, 24 in 2012, 36 in both 2013 and 2014, and 42 in 2015. The sample included at least 2,000 passengers on trains operating south, southwest, west, northwest, and north from downtown Chicago (Figure 2) and included both rush hour and non-rush hour. The number of observations was limited so that no single train accounted for more than $8 \%$ of all observations through 2013 and no more than 5\% in subsequent years. Measures of onboard crowding were not considered due to the carrier's ability to provide seats to the overwhelming majority of riders. (Some passengers nonetheless choose to stand rather to take empty seats when trains are nearly full, suggesting that this variable may be worthy of consideration in future analysis). 


\section{Descriptive Statistics}

The data show a gradual increase in technology use between 2010 and 2015 as well as a shift toward more sophisticated technologies. Perhaps the most salient result is that the share of passengers using mobile commuication devices gradually rose over the five-year project period despite changes in the economic performance of the regional economy. At randomly-selected points, $25.6 \%$ of passengers were engaged with technology in 2010, compared to $38.2 \%$ in 2012, 54.4\% in early 2014, and 56.2\% in 2015 (Figure 3). Since 2014, more than half of passengers have been engaged with personal devices at the observed points, compared to slightly over a quarter in 2010.

FIGURE 3.

Percent of commuter rail riders using mobile communication devices at observed points.

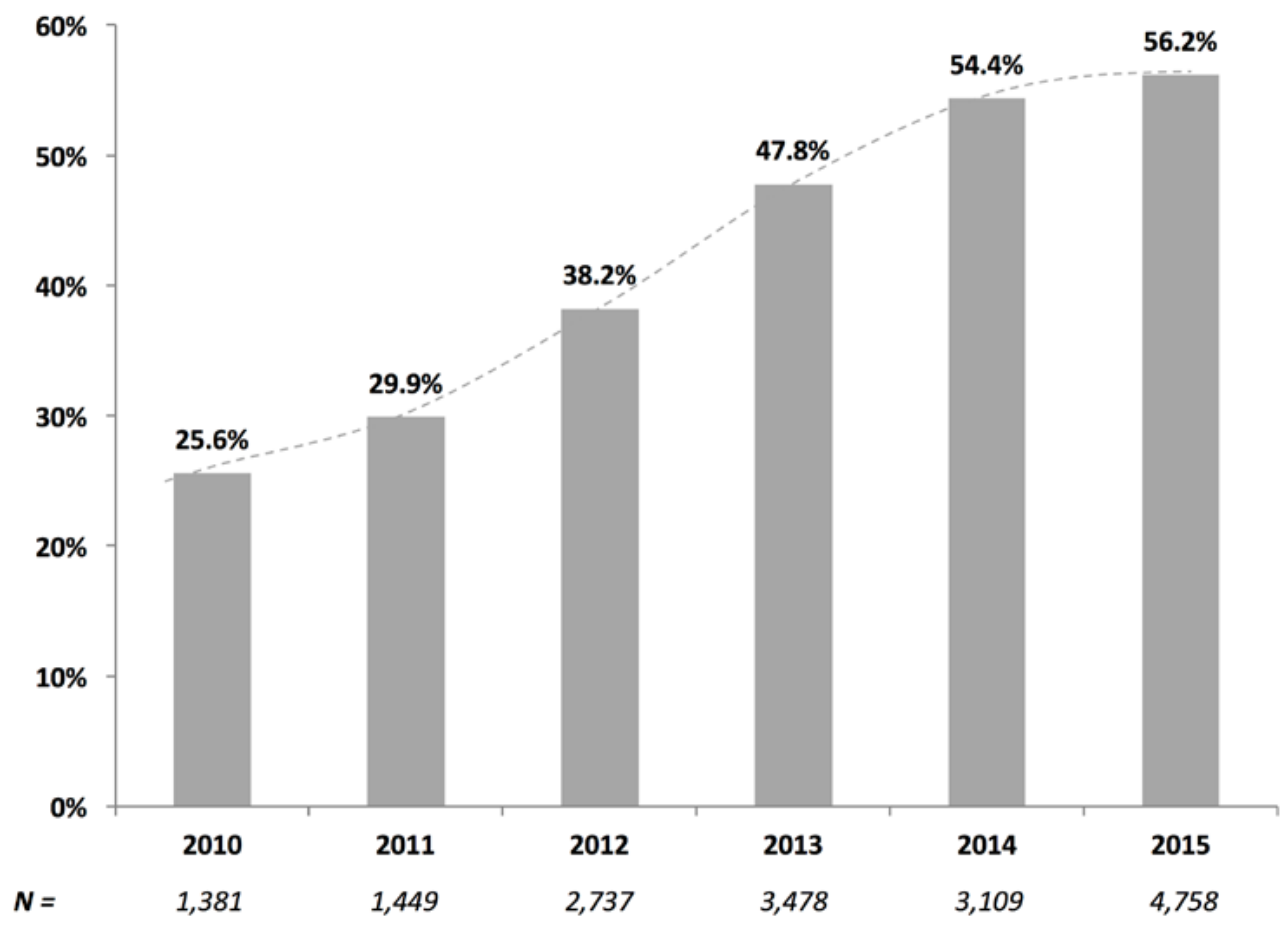

Although the methodology does not allow for measurement of the percentage of passengers who use technology at some point during the trip (which Metra estimates to be as high as $90 \%$ ), the results suggest the intensity of technological engagement has risen steadily over the five-year period. The change in usage between each interval is statistically significant ( $99 \%$ confidence interval) with the compounding rate of growth from 2010-2013 being 23.1\%, compared to just 8.4\% from 2013-2015.

Observations also show that e-reader and tablet usage (tracked as a separate category) has been on the rise since 2012. The small sizes and quick boot-up times of these devices make them well-suited for space-confined environments and trips of shorter duration. Unlike laptops and notebook computers, tablets and e-readers (including "phablets") can be stored easily in a briefcase or purse and take up much less room when in use. In 2012, the first year tablets were measured as a distinct category, just $4.9 \%$ of passengers were using tablets or e-readers. That share rose to $6.4 \%$ in $2013,7.9 \%$ in 2014 , and $9.3 \%$ 
in 2015. As a result, by 2015, about 1 in 11 passengers was using a tablet or e-reader compared to just 1 in 20 in 2012. The share of all mobile devices users engaged with tables and e-readers rose from $12.8 \%$ in 2012 to $16.5 \%$ in 2015, suggesting that, although these devices are becoming more common, they remain far less prevalent than other types of devices.

As more travelers turn to sophisticated devices, such as tablets and e-readers, they increasingly diminish the time spent solely on audio-oriented functions, such as cellphone calls and listening to music. The share of Metra riders performing visuallyoriented tasks at randomly-observed points rose from $13.9 \%$ in 2010 to $44.0 \%$ in 2015 (Figure 4).

FIGURE 4.

Percent of commuter rail riders engaged in visuallyoriented tasks at observed points.

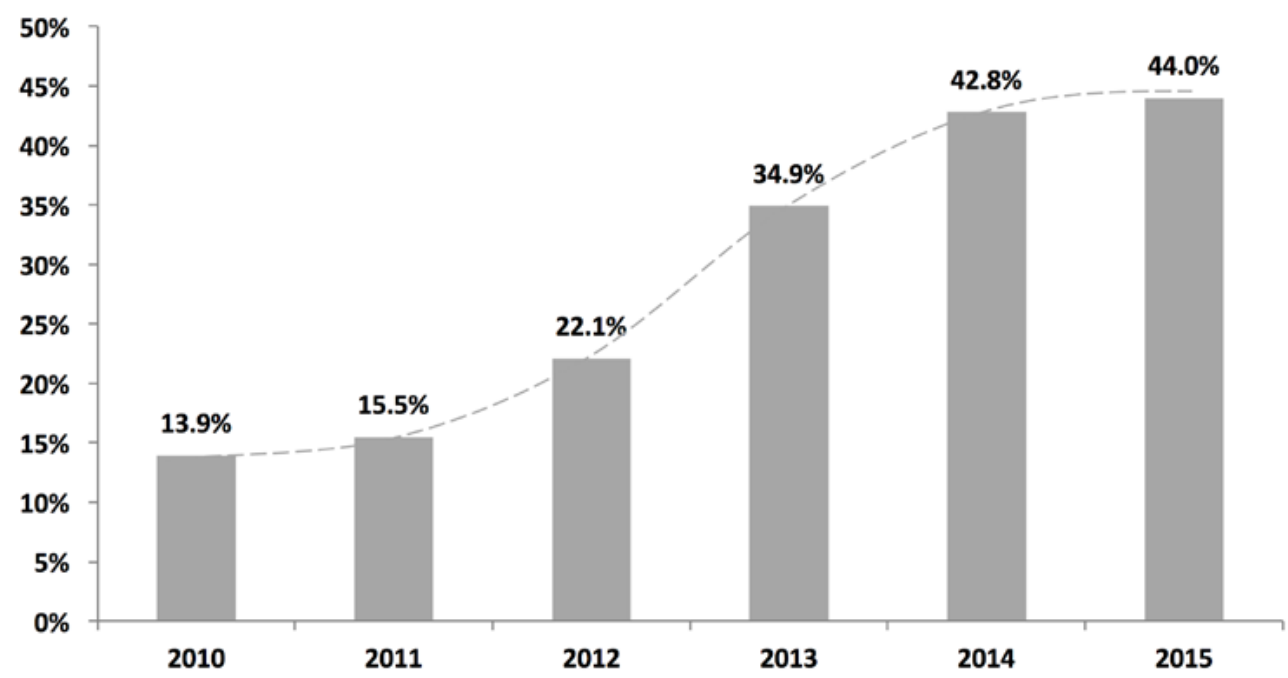

Both Figure 3 and Figure 4 align with the S-curve of technology adoption originally proposed by Rogers (1962). The dotted lines on these figures show how neatly the $\mathrm{S}$-shaped curve fits to the collected data. Both figures shows accelerating growth in device use through 2013, followed by a deceleration, suggesting a flattening-out effect, perhaps due to the growing saturation of mobile devices in the general population. Figure 4 shows a slightly more pronounced S-shaped pattern than Figure 3, with use of visually-oriented activities growing at a compounding annual rate of $34.9 \%$ from 2010 to 2013, compared to just $12.3 \%$ between 2013 and 2015. This suggests that additional gains likely will continue to be made at a much slower rate in the coming years. The policy implications of this are discussed in the conclusion.

The data collected allow for a comparison of technology use by time and direction of travel. As noted in the Appendix, in the most recent year surveyed (2015), the use of technology was significantly higher on outbound trips than inbound trips, which provides evidence that technology use may be more pervasive (and beneficial) to travelers after their workday than before, although the authors cannot determine whether activities are work- or leisure-related. Technology use on outbound trips during the peak period exceeds that on inbound trips during the peak by an even 
wider margin. Both results are statistically significant at a 0.05 level. Please refer to the Appendix for details.

\section{Explanatory Model}

A multiple regression model was developed to further investigate changing patterns of technology use on commuter trains. The analysis encompasses 148 trains surveyed between 2010 and 2015 for which at least 20 observations were recorded on each train. (Eight of the 156 trains had fewer than 20 observations and were omitted due to their small sample size.) The dependent variable is the proportion of passengers on a train using mobile devices, and the independent variables are listed in Table 2.

TABLE 2. Independent Variables

\begin{tabular}{|l|l|}
\hline \multicolumn{2}{|c|}{ Independent Variables } \\
\hline PEAK & $\begin{array}{l}\text { Trains observed between 7:00-9:30 AM and 3:30-7:00 PM Monday through } \\
\text { Friday assigned a value of 1. }\end{array}$ \\
\hline OUTBOUND & Trains traveling outward from central city assigned a value of 1. \\
\hline PEAKFLOW & $\begin{array}{l}\text { Trains servicing inbound commuters during morning peak period and } \\
\text { outbound during evening peak assigned a value of 1. }\end{array}$ \\
\hline YEARS & Number of years passed since first year of data collection (2010). \\
\hline YEARS ${ }^{2}$ & $\begin{array}{l}\text { Square of years passed since first year of data collection (2010). Used to capture } \\
\text { nonlinear relationship. }\end{array}$ \\
\hline INCOME & $\begin{array}{l}\text { Average household income in ZIP codes of all suburban stops served on Metra } \\
\text { line where data collected, derived from American Community Survey data } \\
\text { from 2010. Income measured in \$1,000 annually. }\end{array}$ \\
\hline PEAK*YEARS & $\begin{array}{l}\text { Number of years multiplied by peak travel designator to determine if peak } \\
\text { period differential has risen or declined over time. }\end{array}$ \\
\hline INCOME*YEARS & $\begin{array}{l}\text { Number of years multiplied by income of a route to determine if effects of } \\
\text { income have risen or declined over time. }\end{array}$ \\
\hline OUTBOUND*YEARS & $\begin{array}{l}\text { Number of years multiplied by outbound designator to determine if outbound } \\
\text { differential has risen or declined over time. }\end{array}$ \\
\hline
\end{tabular}

Using a proportion as the dependent variable can lead to certain biases because values are bounded between 0 and 1 . The authors, therefore, considered two sets of results: with and without a Tobit transformation of the dependent variable. The Tobit transformation involves a logarithmic transformation using the formula $\ln (p /(1-p)$. This adjustment results in a dependent variable that is normally distributed but generates coefficients that lack simple intuitive interpretations.

The vast majority of dependent values are clustered near the middle of the range, between 0.3 and 0.7 , and not censored from above or below, and there are no values in the dataset at the extreme ends of the distribution (i.e., less than 0.1 and more than 0.9). The discussion below, therefore, focuses primarily on the standard model, with the Tobit results provided in the Appendix. This standard model also has the advantage of generating coefficients that have a simple and straightforward interpretation. The independent variables used in the model are provided in Table 3. 
TABLE 3.

Results of Multiple Regression Model

\begin{tabular}{|c|c|c|c|c|c|c|c|c|}
\hline & \multicolumn{2}{|c|}{$\begin{array}{c}\text { Model 1: } \\
\text { Time of Day, } \\
\text { Direction of } \\
\text { Travel, + Changes } \\
\text { Over Time }\end{array}$} & \multicolumn{2}{|c|}{$\begin{array}{c}\text { Model 2: } \\
\text { Time of Day, } \\
\text { Direction of } \\
\text { Travel + Changes } \\
\text { Over Time } \\
\text { (Nonlinear) }\end{array}$} & \multicolumn{2}{|c|}{$\begin{array}{c}\text { Model 3: } \\
\text { Direction of } \\
\text { Travel + Changes } \\
\text { Over Time } \\
\text { (Nonlinear), } \\
\text { Route Income }\end{array}$} & \multicolumn{2}{|c|}{$\begin{array}{c}\text { Model 4: } \\
\text { Direction of } \\
\text { Travel, Changes } \\
\text { Over Time } \\
\text { (Nonlinear), } \\
\text { Route Income, } \\
\text { Income-Time } \\
\text { Interaction }\end{array}$} \\
\hline & Coeff. & P Value & Coeff. & P Value & Coeff. & P Value & Coeff. & P Value \\
\hline INTERCEPT & $0.282^{* *}$ & $(0.000)$ & $0.243^{* *}$ & $(.000)$ & $0.123^{*}$ & $(0.023)$ & 0.102 & $(0.278)$ \\
\hline PEAK & 0.021 & $(0.259)$ & 0.025 & $(0.175)$ & 0.022 & $(0.263)$ & 0.021 & $(0.253)$ \\
\hline OUTBOUND & $0.042^{*}$ & $(0.026)$ & $0.039^{*}$ & $(0.037)$ & 0.020 & $(0.051)$ & 0.035 & $(0.053)$ \\
\hline YEAR & $0.066^{* *}$ & $(0.000)$ & $0.123^{* *}$ & $(0.000)$ & $0.120^{* *}$ & $(0.000)$ & $0.129 * *$ & (0.003) \\
\hline $\mathrm{YEAR}^{2}$ & & & $-0.014^{*}$ & $(0.018)$ & $-0.012^{*}$ & $(0.031)$ & $-0.012^{*}$ & $(0.031)$ \\
\hline INCOME & & & & & $0.002^{* *}$ & (0.009) & 0.002 & (0.109) \\
\hline INCOME*YEAR & & & & & & & -0.000 & (0.793) \\
\hline $\mathrm{R}^{2}$ & 0.399 & & 0.422 & & 00.449 & & 0.450 & \\
\hline ADJ. $R^{2}$ & 0.386 & & 0.406 & & 00.430 & & 0.426 & \\
\hline
\end{tabular}

Dependent variable: Proportion of travelers using mobile communication devices Observations $=148$ trains.

*Significant at 0.05 .

**Significant at 0.01 .

The dependent variables PEAK, OUTBOUND, and PEAKFLOW relate to the type and timing of service provided. The variable YEARS represents the number of years elapsed since the base year, 2010, and is intended to capture the average change in technology per year due to exogenous factors that have occurred over time, such as changing consumer habits and greater adoption of $3 \mathrm{G}$ and $4 \mathrm{G}$ services. A polynomial (squared) version of this variable, YEARS ${ }^{2}$, captures the nonlinear relationship observed in Figures 3 and 4.

The INCOME variable is the mean of the median household income in the zip codes where suburban Metra stations are located for each line. Tabulating these values involved collecting data from 140 ZIP codes in which Metra stations are located. Values were tabulated by Metra line; the Union Pacific-North line, for example, is located in the ZIP code with the highest household income $(\$ 99,600)$, followed by the BNSF line $(\$ 82,580)$. The Metra Electric $(\$ 60,360)$ and South Shore lines $(\$ 56,000)$, both serving the south part of the region, have the lowest income values. Although INCOME is a simplified estimate, it serves as a useful measure of the affluence of the corridor in which the train operates. Income may be important due to the "digital divide" that exists in the adoption of technology as well as the higher opportunity cost affluent passengers face when spending time on the train. Three interaction terms are used to evaluate how the effects of these variables have changed over time.

The analysis considered four models using the proportion of technology use as the dependent variable and the independent variables discussed above. The models are discussed below, and the statistical results are presented in Table 4. 
TABLE 4.

Rates of Technology Use by Time and Direction of Travel \begin{tabular}{l|l} 
Using Any Technology & Conducting Visual Task
\end{tabular}

\begin{tabular}{|l|c|c|c|c|c|}
\cline { 2 - 6 } \multicolumn{1}{c|}{} & Sample Size & Yes & No & Yes & No \\
\hline Peak & 2,925 & $56.4 \%$ & $43.6 \%$ & $45.7 \%$ & $54.2 \%$ \\
\hline Off-Peak & 1,823 & $55.8 \%$ & $44.2 \%$ & $41.0 \%$ & $59.0 \%$ \\
\hline \multicolumn{2}{|c|}{} & \multicolumn{2}{c|}{$\mathrm{X}_{2}=0.1656$} & \multicolumn{2}{c|}{$\mathrm{X}_{2}=10.2156^{*}$} \\
\hline Inbound & 1,844 & $51.1 \%$ & $48.9 \%$ & $36.9 \%$ & $63.1 \%$ \\
\hline Outbound & 2,904 & $59.5 \%$ & $40.5 \%$ & $48.3 \%$ & $51.7 \%$ \\
\hline \multicolumn{2}{|c|}{$\mathrm{X}_{2}=32.2167^{*}$} & $\mathrm{X}_{2}=60.2585^{*}$ \\
\hline Peak Inbound & 1,207 & $49.0 \%$ & $61.0 \%$ & $36.4 \%$ & $63.6 \%$ \\
\hline Peak Outbound & 1,718 & $62.7 \%$ & $57.3 \%$ & $52.1 \%$ & $49.9 \%$ \\
\hline & \multicolumn{2}{|c|}{$\mathrm{X}_{2}=46.7688^{*}$} & \multicolumn{2}{c|}{$\mathrm{X}_{2}=67.0287^{*}$} \\
\hline
\end{tabular}

* Denotes significance at 0.01 level.

\section{Model 1: Basic Linear Model}

This model evaluates how technology use has changed over time while controlling for the direction of travel (OUTBOUND), the time of travel (PEAK), and the number of years that passed since 2010 (YEAR). The results shows that the proportion of riders using mobile devices has risen an average of $6.6 \%$ annually (YEAR) and that this change is statistically significant. The OUTBOUND variable was also significant and indicates that device use is $4.2 \%$ higher on outbound trips than on inbound trips. The time of travel (PEAK) did not have a statistically significant impact on rates of mobile device use. The addition of the OUTBOUND*YEAR variable did not significantly improve the model's predictive ability (it produced a coefficient that was positive but not statistically significant) and was dropped. Model 1 explains $39 \%$ (Adj. $R^{2}=0.386$ ) of observed variations in mobile device use.

\section{Model 2: Nonlinear Rate of Growth in Technology Use}

Model 2 is similar to Model 1 but includes both the YEAR and YEAR ${ }^{2}$ variable to assess whether the use of devices changed in a nonlinear manner. The coefficient for YEAR remains positive and significant, whereas coefficient for $\mathrm{YEAR}^{2}$ is negative and also statistically significant. This indicates that although device use increased, it did so at a declining rate, a finding consistent with the S-shaped pattern in Figures 2 and 3 . The OUTBOUND variable remains statistically significant, although its coefficient value decreased slightly.

\section{Model 3: Effects of Income}

Model 3 considers how device usage is affected by the average income of the commuter line by adding the INCOME variable to Model 2 . The INCOME variable is statistically significant and indicates that for each $\$ 1,000$ of average income on the line, there is an increase of $0.21 \%$ in device use among passengers riding that line. This suggests that the highest-income line has observed device use that is about $6 \%$ higher than the lowest 
income line in our study. Inclusion of the INCOME variables results in the OUTBOUND variable being no longer significant, suggesting that the affluence of riders has a greater impact on device usage rates than does the direction of travel.

\section{Model 4: The Changing Effects of Income over Time}

The final model evaluates how the effects of income have changed over time by considering an interaction variable between income and years of time elapsed since 2010 (INCOME*YEARS). Although the INCOME coefficient remains roughly the same, it is no longer significant in this model; the interaction variable INCOME*TIME is also not significant. Based on these results, there is little evidence to suggest that the effects of income are falling significantly over time even as mobile device ownership expands. Nevertheless, the coefficient is negative, and it is possible that this effect could be definitively demonstrated with a larger sample. The addition of the interaction term lowered adjusted $\mathrm{R}^{2}$ from 0.430 to 0.426 .

A variety of other variables also were considered, including PEAKFLOW (indicating whether the train involved a traditional commuting schedule), but this variable was not significant when the OUTBOUND variable was included. The interaction effects between either OUTBOUND and PEAK with YEARS also were not statistically significant in any of the models.

\section{Conclusions}

Metra faces two distinct trends with regard to the use of mobile communication devices. First, passengers continue to shift toward more visually-intensive activities that are difficult or impossible to safely perform when using other forms of transportation, such as biking, driving, or walking. This suggests the intensity of activities being conducted is growing. At the same time, the overall rate of growth of device use by passengers has slowed. Mobile device usage is following the S-shaped pattern identified by Rogers (1962). Cultivating further gains in technology use may require efforts to cater to the "late majority" (those skeptical of innovation or with less financial liquidity) or "laggards" (those who often have an aversion to change). The findings indicate that rates of device use also are influenced by income, supporting claims that a digital divide persists on the basis of average income. Although the data show that traditional commuters traveling outbound are the heaviest users of mobile devices, the adoption of technology has progressed far enough along the $\mathrm{S}$-curve that the differential in usage between the peak/off-peak periods is small.

The declining rates of growth in device use suggests that agencies should exercise caution in spending large sums to add amenities such as Wi-Fi to commuter trains, as the opportunities for expanding passenger use of technology may have fallen. Nevertheless, "tech-friendly" amenities may positively contribute to broader passenger satisfaction. Some of the most attractive opportunities may exist along routes serving lower-income riders, where technology use has not progressed as far along the S-curve as on higher-income lines. Although ubiquitous Wi-Fi service may be cost-prohibitive, 
providing working electrical outlets and developing apps that improve the on-board experience may be reasonable short-term moves. Likewise, the prevalence of mobile device use among travelers may provide new opportunities for transit agencies to collect advertising revenue by partnering with "smart city" technology companies that provide real-time and geographically-specific advertising to passengers.

\section{APPENDIX}

The results from 2015 show that $56.4 \%$ of passengers on peak-period trips used technology, compared to $55.8 \%$ on off-peak trips (Table 4). This difference, however, is not statistically significant. An estimated $59.5 \%$ use technology on outbound trips, compared to $51.1 \%$ on inbound trips, a difference significant at a 0.01 level. A gap also was observed among inbound and outbound passengers with respect to visual tasks (see column b of Table 4). On outbound trips, $48.3 \%$ were engaged in visual tasks, compared to $36.9 \%$ on inbound trips. Furthermore, the share of technology use on outbound trips during the peak period exceeded that on inbound trips during the peak by $61.7 \%$ to $49.0 \%$, a statistically significant difference. The gap was much smaller for off-peak trips.

A summary of the regression analysis with the Tobit transportation is shown in Table 5.

TABLE 5.

\begin{tabular}{|l|l|l|l|l|l|l|l|l|}
\hline & \multicolumn{2}{|c|}{$\begin{array}{c}\text { 1. Time of day, } \\
\text { Direction of } \\
\text { Travel, + Changes } \\
\text { Over Time }\end{array}$} & $\begin{array}{c}\text { 2. Time of day, } \\
\text { Direction of travel } \\
\text { +Changes Over } \\
\text { Time (Nonlinear) }\end{array}$ & $\begin{array}{c}\text { 3. Direction of } \\
\text { Travel + Changes } \\
\text { Over Time } \\
\text { (Nonlinear), } \\
\text { Route Income }\end{array}$ & $\begin{array}{c}\text { 4. Direction of } \\
\text { Travel, Changes } \\
\text { Over Time } \\
\text { (Nonlinear), Route } \\
\text { Income, Income- } \\
\text { Time Interaction }\end{array}$ \\
\hline & Coeff. & P Value & Coeff. & P Value & Coeff. & P Value & Coeff. & P Value \\
\hline INTERCEPT & $-0.961^{* *}$ & $(0.000)$ & $-1.12^{* *}$ & $(0.000)$ & $-1.63^{* *}$ & $(0.000)$ & $-1.83^{* *}$ & $(0.000)$ \\
\hline PEAK & 0.021 & $(0.410)$ & 0.089 & $(0.315)$ & 0.070 & $(0.428)$ & 0.023 & $(0.763)$ \\
\hline OUTBOUND & $0.074^{*}$ & $(0.024)$ & $0.192^{*}$ & $(0.033)$ & $0.179^{*}$ & $(0.045)$ & 0.025 & $(0.053)$ \\
\hline TIME & $0.288^{* *}$ & $(0.000)$ & $0.524^{* *}$ & $(0.000)$ & $0.501^{* *}$ & $(0.000)$ & $0.626^{*}$ & $(0.002)$ \\
\hline TIME ${ }^{2}$ & & & -0.0054 & $(0.052)$ & -0.048 & $(0.078)$ & -0.050 & $(0.054)$ \\
\hline INCOME & & & & & $0.003^{*}$ & $(0.023)$ & 0.010 & $(0.060)$ \\
\hline INCOME*TIME & & & & & & & -0.001 & $(0.466)$ \\
\hline$R^{2}$ & 0.363 & & 0.380 & & 0.403 & & 0.435 & \\
\hline ADJ. R ${ }^{2}$ & 0.350 & & 0.363 & & 0.381 & & 0.411 & \\
\hline
\end{tabular}

Dependent variable: Proportion of travelers using electronic devices with TOBIT transformation

Observations $=148$ trains

*Significant at 0.05 .

**Significant at $0 . .01$. 


\section{References}

American Public Transportation Association. 2016. "Public Transportation Ridership Report, Fourth Quarter 2015." March 2. http://www.apta.com/resources/statistics/ Pages/ridershipreport.aspx, accessed May 27, 2016.

Andreev, Pavel, Ilan Salomon, and Nava Pliskin. 2010. "Review: State of Teleactivities." Transportation Research. Part C, Emerging Technologies, 18: 3-20.

Barbeau, S. J., M. A. Labrador, N. L. Georggi, P. L. Winters, and R. A. Perez. 2010. "The Travel Assistance Device: Utilizing GPS-enabled Mobile Phones to Aid Transit Riders with Special Needs." IET Intelligent Transportation Systems, 4(1): 12-23.

Brakewood, Candace, et al. 2014. "Forecasting Mobile Ticketing Adoption on Commuter Rail." Journal of Public Transportation 17(1) 1-19.

Bull, Michael. 2000. Sounding Out the City: Personal Stereos and the Management of Everyday Life. Oxford: Berg.

Farley, Tom. 2005. “Mobile Telephone History.” Privateline.com, http://www.privateline. com/wp-content/uploads/2016/01/TelenorPage_022-034.pdf.

Frei, Charlotee, and Hani S. Mahmassani. 2011. "Private Time on Public Transit: Dimensions of Information and Telecommunication Use of Chicago Transit Riders." Presentation, Annual Transport Chicago Conference, Chicago, IL, June 3.

Holley, David, Juliet Jain, and Glenn Lyons. 2008. "Understanding Business Travel Time Use and its Place in the Working Day." Time \& Society 17(1): 27-46.

Golob, Thomas F., and Amelia C. Regan. 2001. "Impacts of Information Technology on Personal Travel and Commercial Vehicle Operations: Research Challenges and Opportunities." Transportation Research. Part C, Emerging Technologies, 9(1): 87-121.

Guo, Zhan, Alexandra Derian, and Jinhua Zhao. 2015. "Smart Devices and Travel Time Use by Bus Passengers in Vancouver, Canada." International Journal of Sustainable Transportation, 9(5): 335-347.

Hess, S., and G. Spitz. 2016. "How Much Do Attitudes and Values Matter in Mode Choice?" Paper presented at 95th Annual Meeting of the Transportation Research Board, Washington, DC.

Jackson, Linda A., Zhao Yong, Anthony Kolenic III, Hiram E. Fitzgerald, Rena Harold, and Alexander Von Eye. 2008. "Race, Gender, and Information Technology Use: The New Digital Divide." CyberPsychology \& Behavior, 11(4): 437-442.

Jain, Juliet, and Glen Lyons. 2008. "The Gift of Travel Time." Journal of Transport Geography, 16(2): 81-89.

Kim, Dae-Young, Jungkun Park, and Alastair M. Morrison. 2008. "A Model of Traveler

Acceptance of Mobile Technology." International Journal of Tourism Research, 10(5): 393- 407. 
Lyons, Glenn, Juliet Jain, and David Holley. 2007. "The Use of Travel Time by Rail Passengers in Great Britain." Transportation Research Part A, 41(1): 107-120.

Metra. 2013. "2011 Regional Transportation Authority Customer Satisfaction Study." January. www.metrarail.com, accessed March 1, 2016.

Metra. 2015. "Metra Will Test Wi-Fi on 10 Rail Cars Systemwide." September 25. https:// metrarail.com/metra/en/home/utility_landing/newsroom/newsroom/metra-totest-Wi-Fi-on-10-cars-systemwide.html, accessed February 16, 2011.

Metropolitan Boston Transit Authority (MBTA). 2013. "MBTA Announces Wi-Fi Service Sponsorship Program." March 1. http://www.mbta.com/about_the_mbta/news_ events/?id=26452, accessed February 11, 2016.

Mokhtarian, Patricia L., and Ilan Salomon. 2001. "How Derived is the Demand for Travel? Some Conceptual and Measurement Considerations." Transportation Research Part A, 35(8): 695-719.

Mokhtarian, Patricia L., Ilan Salomon, and Susan L Handy. 2006. "The Impacts of ICT On Leisure Activities and Travel: A Conceptual Exploration." Transportation, 33(3): 263-289.

Neff, Jack. 2010. "Young Drivers Shift Gears: Is Digital Revolution Driving Decline in U.S. Car Culture?" Advertising Age. May 31. http://adage.com/article/digital/digitalrevolution-driving- decline-u-s-car-culture/144155/.

Ninth Decimal (formerly JiWire). "Measurement." http://www.ninthdecimal.com/ location-conversion-index-Ici-measurement, accessed February 11, 2016.

Ohmori, Nobuaki, and Noboru Harata. 2009. "How Different are Activities While Commuting by Train? A Case in Tokyo." Tijdschrift voor Economische en Sociale Geografie, 34(1): 547-561.

Pew Charitable Trust. 2016. "Who Uses Mobile Payments: Survey Findings on Consumer Opinions, Experiences."

Rail Engineer Team. 2015. "Train Connectivity-The Future Beckons." RailEngineer. September 1.. http://www.railengineer.uk/2015/09/11/train-connectivity-the-futurebeckons/, accessed February 2016.

Rogers, Everett M. 1962. Diffusion of Innovations. London: The Free Press, Collier McMillan Publishers.

Russell, Marie, Rachel Price, Louise Signal, James Stanley, Zachery Gerring, and Jacqueline Cumming. 2011. "What do Passengers do During Travel Time? Structured Observations on Buses and Trains." Journal of Public Transportation, 14(3): 123-146.

Salomon, Ilan. 1998. "Technological Change and Social Forecasting: The Case of Telecommuting as a Travel Substitute." Transportation Research Part C, 6(1-2): $17-45$.

Sasaki, Kuniaki, and Kazuo Nishii. 2010. "Measurement of Intention to Travel: Considering the Effect of Telecommunications on Trips." Transportation Research Part C: Emerging Technologies, 18(1): 36-44. 
Schwieterman, Joseph P., and Lauren A. Fischer. 2011. "Variations in the Rates of Passengers Usage of Portable Technology on Intercity Buses, Trains, and Planes: Implications for Transportation Planning." Journal of Transportation Law, Logistics and Policy, 78(1): 435-444.

Simun, Miriam. 1009. "My Music, My World: Using the MP3 Player to Shape Experience in London." New Media \& Society, 11(6): 921-941.

Skanland, M. 2011. "Use of MP3 Players as a Coping Resource." Music and Arts in Action, $3(2): 15-32$.

Susilo, Yusak O., Glenn Lyons, Juliet Jain, and Steve Atkins. 2012. "Rail Passengers' Time Use and Utility Assessment: 2010 Findings from Great Britain with Multivariate Analysis." Proc. 91st Annual Meeting of the Transportation Research Board, Washington, DC, January; forthcoming, Transportation Research Record.

Tang, L., and Thakuriah, P.V. 2012. "Ridership effects of real-time bus information system: A Case Study in the City of Chicago." Transportation Research Part C: Emerging Technologies, 22: 146-161.

Transportation Research Board. 2016. Interregional Travel: A New Perspective for Policymaking, Special Report 320. National Academy of Sciences.

U.S. Public Interest Research Group Education Fund. 2013. "Our Changing Relationship with Driving and the Implications for America's Future." U.S. Public Interest Research Group. Spring 2013.

Van der Waerden, Peter, Harry Timmermans, and Rob van Neerven. 2009. "Extent, Nature, and Covariates of Multitasking of Rail Passengers in an Urban Corridor: A Dutch Case Study." Transportation Research Record, 40(2110): 106-111.

Windmiller, S., T. Hennessy, and K .E. Watkins. 2014. "Accessibility of Communication Technology and the Rider Experience Case Study of Saint Louis, Missouri, Metro." Transportation Research Record, 2415/Transit: 118-126.

Yoshii, Toshio, and Kuniaki Sasaki. 2010. "Information/Communication Technologies and Travel Behaviour." Transportation Research Part C: Emerging Technologies, 18(1): 1-2.

\section{About the Authors}

Joseph P. SChWIETERMAN, Ph.D. (jschwiet@depaul.edu) is a Professor in the School of Public Service and Director of the Chaddick Institute for Metropolitan Development at DePaul University in Chicago.

LAURen Ames Fischer is in the Graduate School of Architecture, Planning, and Preservation at Columbia University. 